\title{
Epitaxial growth of celestite on barite (001) face at a molecular scale
}

\author{
Nuria Sánchez-Pastor ${ }^{a}$, Carlos M. Pina ${ }^{\text {a,* }}$, José Manuel Astilleros ${ }^{a}$, \\ Lurdes Fernández-Díaz a , Andrew Putnis b
}

a Dpto. Cristalografía y Mineralogía, Universidad Complutense de Madrid, E-28040 Madrid, Spain

b Institut für Mineralogie, Universität Münster, Corrensstraße 24, D-48149, Germany

\begin{abstract}
In situ AFM experiments have been conducted in order to obtain information about kinetics of celestite epitaxial growth on barite. Growth has been promoted by passing aqueous solutions supersaturated with respect to celestite over

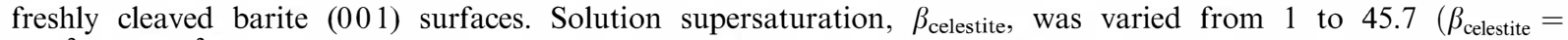
$\left.a\left(\mathrm{Sr}^{2+}\right) \cdot a\left(\mathrm{SO}_{4}^{2-}\right) / K_{\mathrm{sp}, \mathrm{cel}}\right)$. At supersaturations below 10 neither two-dimensional nucleation neither step advancement are observed on barite $(001)$ surfaces. However, once the two-dimensional nucleation barrier is overcome $\left(\beta_{\text {celes- }}\right.$ tite $>10$ ), nuclei preferentially form on cleavage steps parallel to [100], [110] and [120] directions and more scarcely on terraces. The subsequent growth of two-dimensional nuclei leads to the development of celestite "islands". Their morphology is defined by (001) face and $\{210\}$ and $\{100\}$ forms and can be explained on the basis of PBC theory. The coalescence of such islands results in the formation of a homogeneous $\mathrm{SrSO}_{4}$ layer. Growth rates along [0 01 1] direction have been measured for the whole supersaturation range. The growth rate equation for "Birth and Spread" crystal growth mechanism has been successfully fitted to our experimental data. The fitting process has provided basic growth parameters in a good agreement with theoretical ones. Both the high transitional supersaturation required for twodimensional nucleation and the high interfacial energy value obtained from the fitting of the "Birth and Spread" equation $\left(\sigma_{001}^{\text {cel bar }}=0.137 \mathrm{~J} / \mathrm{m}^{2}\right)$ indicate low affinity of $\mathrm{SrSO}_{4}$ growth units for barite $(001)$ faces. This is consistent with the relative high mismatch between celestite and barite structure. The behaviour of the epitaxial growth described in this work can help to interpret the oscillatory zoning frequently occurring in both natural and synthetic crystals of the $\mathrm{Ba}_{x} \mathrm{Sr}_{1-x} \mathrm{SO}_{4}$ solid solution.
\end{abstract}

\footnotetext{
${ }^{*}$ Corresponding author. Tel.: +34 913944879; fax: +34 913944872.

E-mail addresses: nsanchez@geo.ucm.es (N. Sánchez-Pastor), cmpina@geo.ucm.es (C.M. Pina), jmastill@geo.ucm.es (J.M. Astilleros), lfdiaz@geo.ucm.es (L. Fernández-Díaz), putnis@nwz.uni-muenster.de (A. Putnis).
} 


\section{Introduction}

One of the most interesting and intriguing phenomena observed in natural and synthetic crystals of the $\mathrm{Ba}_{x} \mathrm{Sr}_{1-x} \mathrm{SO}_{4}$ solid solution is the development of compositional oscillatory zoning. Frequently, such a zoning consists of an alternation of Ba-rich and Sr-rich layers and, as previous works have demonstrated, the composition and width of such layers are quite independent from the composition of the fluid from which the crystal grows [1-3]. On the contrary, it seems that the growing crystal exerts a certain control on its own chemical composition [4]. Most of the models proposed in the last decades to explain compositional oscillatory zoning in binary solid solutions consider autocatalytic growth processes [5-7]. According to these models, once a crystal face starts to grow with a composition rich in one end-member of the solid solution, further crystallization of such a composition is promoted. This leads to the depletion of the surrounding aqueous solution in that end-member and, eventually, the growing layer switches to a composition rich in the other end-member. The oscillatory zoning results from a cyclic repetition of this process. Although these models provide a satisfactory general explanation for the observed spatio-temporal patterns in zoned crystals, the ultimate microscopic factors involved in the development of compositional patterns remain unknown. Obviously, such factors are determined by the aqueous solution-crystal interface interactions during growth. The growth behaviour at a molecular scale of both barite and celestite $(\mathbf{0 0 1})$ surfaces has been extensively studied during the last decade [8-12, and references therein]. These works have provided information about the control that surface structure exerts on both the nanotopographic features and the kinetics of the growth process.

In this work we present Atomic Force Microscopy (AFM) observations of the epitaxial growth of pure celestite on barite $(\mathbf{0 1})$ surfaces. Sequences of AFM images were collected during growth for a wide range of supersaturations with respect to celestite. From these images we have obtained the following information: (i) a systematic record of the changes in microtopography occurring during the growth process within a wide range of supersaturations for celestite and (ii) growth rates along [001] direction as a function of supersaturation. While microtopographic features are interpreted on the basis of Periodic Bond Chains (PBC) theory, the growth kinetics of $(\mathbf{0 1} 1)$ face is explained by using the Birth and Spread twodimensional nucleation model for crystal growth from solution.

\section{Experimental procedure}

Experiments were performed at room temperature in a fluid cell of a Digital Instruments Multimode Atomic Force Microscope, working in contact mode. Nucleation and growth were studied on a substrate of natural barite crystals. These crystals were cleaved parallel to $(001)$ faces before each experiment and placed in the fluid cell of the AFM. A number of aqueous solutions with different supersaturations were passed over the substrate to promote celestite nucleation. Supersaturation with respect to celestite was calculated using the expression: $\boldsymbol{\beta}_{\text {celestite }}=a\left(\mathrm{Sr}^{2+}\right) \cdot a\left(\mathrm{SO}_{4}^{2-}\right) /$ $K_{\text {sp ,cel }}$ (where $K_{\mathrm{sp}, \mathrm{cel}}=1 \mathbf{0}^{-6.63}$ is the solubility product for celestite). Solution compositions and supersaturations with respect to celestite are listed in Table 1. Solutions with supersaturations for celestite in the range from $\boldsymbol{\beta}_{\text {celestite }}=1$ to $\boldsymbol{\beta}_{\text {celestite }}=45.7$ were used. The activity coefficients for $\mathrm{Sr}^{2+}$ and $\mathrm{SO}_{4}^{2-}$ ionic species were calculated using the program PHREEQC [13]. To avoid solution/sample equilibrium a flow of solution was maintained by injecting fresh solution at intervals of about 1 min between each AFM scan. In those experiments in which two-dimensional nucleation was observed, nuclei growth rates were measured along [001] direction. Measurements were carried out on height AFM images corresponding to different 


\begin{tabular}{|c|c|c|c|c|c|}
\hline \multirow{2}{*}{$\begin{array}{l}\text { Experiment } \\
\text { number }\end{array}$} & \multicolumn{4}{|c|}{ 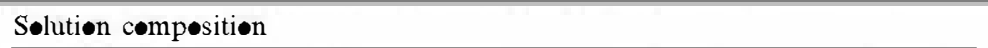 } & \multirow{2}{*}{$\begin{array}{l}\text { Supersaturatiøn } \\
\boldsymbol{\beta}_{\text {celestite }}\end{array}$} \\
\hline & $\mathrm{SrCl}_{2}(\mathrm{~mm} \bullet \mathrm{l} / \mathrm{l})$ & $\mathrm{Na}_{2} \mathrm{~S}_{4}(\mathrm{~mm} \bullet \mathrm{l} / \mathrm{l})$ & $a\left(\mathrm{Sr}^{2+}\right)$ & $a\left(\mathrm{SO}_{4}^{2}\right)$ & \\
\hline 1 & 0.7 & 0.7 & $4.9 \times 10^{-4}$ & $4.9 \times 10^{-4}$ & 1 \\
\hline 3 & 1.4 & 1.4 & $8.7 \times 10^{-4}$ & $8.6 \times 10^{-4}$ & 3.24 \\
\hline 4 & 1.6 & 1.6 & $9.7 \times 10^{-4}$ & $9.5 \times 10^{-4}$ & 3.98 \\
\hline 5 & 1.8 & 1.8 & $1.0 \times 10^{-3}$ & $1.0 \times 10^{-3}$ & 4.79 \\
\hline 8 & 3.5 & 3.5 & $1.7 \times 10^{-3}$ & $1.6 \times 10^{-3}$ & 12.58 \\
\hline 9 & 4 & 4 & $1.9 \times 10^{-3}$ & $1.9 \times 10^{-3}$ & 15.49 \\
\hline 10 & 4.5 & 4.5 & $2.0 \times 10^{-3}$ & $2.0 \times 10^{-3}$ & 18.19 \\
\hline 11 & 5 & 5 & $2.2 \times 10^{-3}$ & $2.1 \times 10^{-3}$ & 20.89 \\
\hline 12 & 5.5 & 5.5 & $2.4 \times 10^{-3}$ & $2.3 \times 10^{-3}$ & 23.99 \\
\hline 17 & 8 & 8 & $3.1 \times 10^{-3}$ & $2.9 \times 10^{-3}$ & 39.81 \\
\hline 18 & 8.5 & 8.5 & $3.2 \times 10^{-3}$ & $3.0 \times 10^{-3}$ & 42.66 \\
\hline 19 & 9 & 9 & $3.3 \times 10^{-3}$ & $3.1 \times 10^{-3}$ & 45.7 \\
\hline
\end{tabular}

runs of the same experiment (from 3 to 5 runs each) in order to minimize apparent variations in growth rates. All the images presented in this work were taken in constant force mode while displaying the cantilever deflection signal.

\section{Atomic force microscopy observations}

\subsection{Microtopography of barite (001) cleavage surfaces}

Freshly cleaved barite $(001)$ surfaces observed with AFM show flat terraces separated by a number of cleavage steps one unit cell in height $(7.15 \AA)$. Step density depends on the cleavage process and it usually varies from $\mathbf{0 . 1 2}$ to 0.2 steps $/ \mu \mathrm{m}^{2}$. The orientation of cleavage steps is presumably related to directions of weaker $\mathrm{SO}_{4}^{2-}-\mathrm{Ba}^{2+}$ bonds along the structure. Our measurements of barite cleavage step directions, carried out on barite $(01)$ faces of known orientation, indicate that most of them are parallel to [100], [110], and [120] crystallographic directions (see Fig. 1).

\subsection{Epitaxial growth of celestite on barite (001) face}

When aqueous solutions with moderate supersaturations for celestite $\left(\boldsymbol{\beta}_{\text {celestite }}<12.58\right)$ flow on barite (01) surfaces (solutions 1-7 in Table 1) no changes in the microtopography are detected for long observation times (more than $20 \mathrm{~min}$, growth rates $<0.02 \mathrm{~nm} / \mathrm{s}$ ). Even cleavage steps remain static without showing any measurable advancement. However, the behaviour is different for solutions with higher supersaturations with respect to celestite. For $\boldsymbol{\beta}_{\text {celestite }}>10$ AFM images show that, a few seconds after injecting the solution in the fluid cell, two-dimensional nuclei form on barite $(01)$ surfaces. The time elapsed between injection and observation of first nuclei depends on supersaturation, i.e. the incubation time decreases as $\boldsymbol{\beta}_{\text {celestite }}$ increases.

On barite $(001)$ surfaces two-dimensional nuclei of celestite preferentially form on cleavage steps. However, nucleation density varies depending on the crystallographic orientation of cleavage steps. This is clearly observed at the early stages of nucleation. Thus, whereas the number of nuclei is 

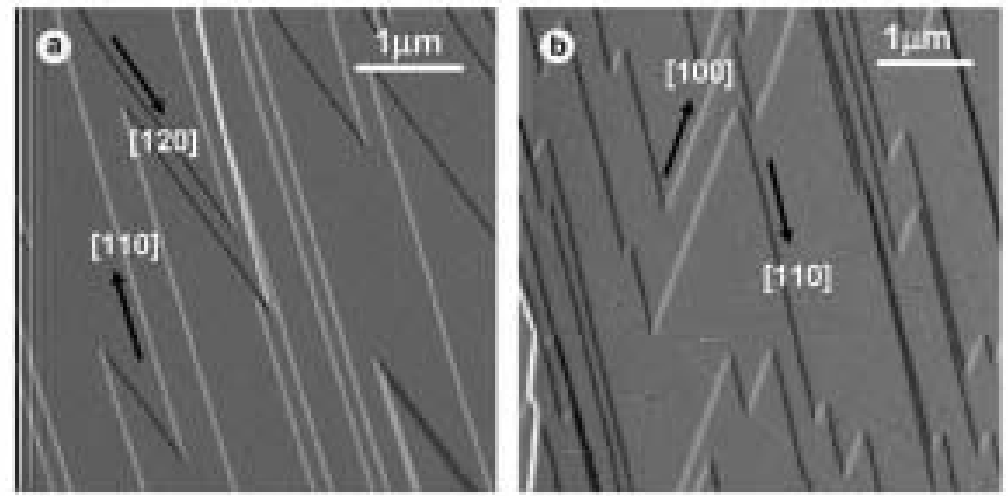

Fis. 1. AFM images of typical barite $(\mathbf{0 1})$ cleavage surfaces. crystalløgraphic directiøns, (b) surface with cleavage steps parallel t•

(a) Surface with cleavage steps parallel to [120] and [110] [100] and [110] directions.
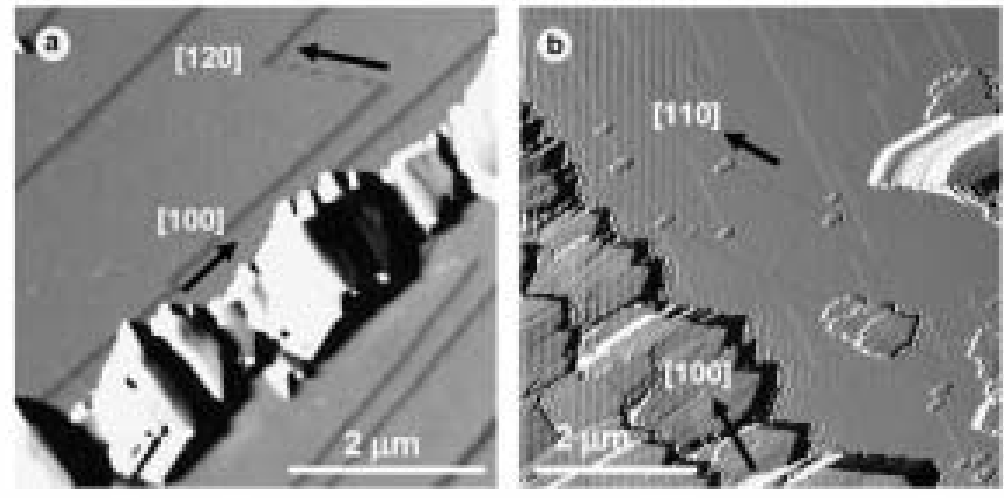

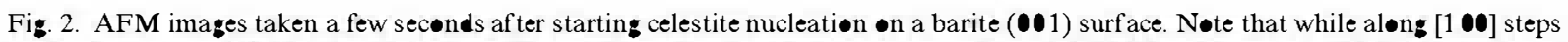

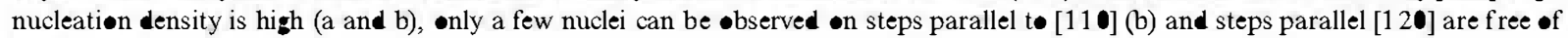
nuclei (a).

very small on steps parallel to [120] directions, nucleation density is higher along [010] steps and even higher along [100] steps (Fig. 2). However, such differences in nucleation density along different cleavage steps become less evident when aqueous solutions with high supersaturations are used. In all the cases nuclei rapidly coalesce forming "crusts" along cleavage steps.

Nucleation is scarcer on terraces and twodimensional nuclei do not spread easily on barite (01) surfaces. The growth of isolated nuclei rapidly leads to the development of two-dimensional islands with a characteristic polygonal morphology defined by $(001)$ face and $\{210\}$ and $\{100\}$ forms (see Fig. 3). Moreover, celestite two-dimensional islands are oriented with respect to the bar- ite $(001)$ substrate and, therefore, the growth must be considered as an epitaxial growth of pure celestite on barite. Goniometric measurements of the islands with respect to the cleavage steps indicate that celestite overgrowth and barite substrate have the same crystallographic orientation, i.e. unit cell vectors are parallel.

Once growth starts, further two-dimensional nucleation is more frequent on newly-grown celestite layers than on the original barite substrate. As a result, a few minutes after starting growth, some regions of the original substrate are covered by a celestite layer of several hundreds $\mathrm{nm}$ in height, while others are free of nuclei. However, as growth proceeds, nuclei formed on terraces and cleavage steps coalesce resulting in the covering of extended 


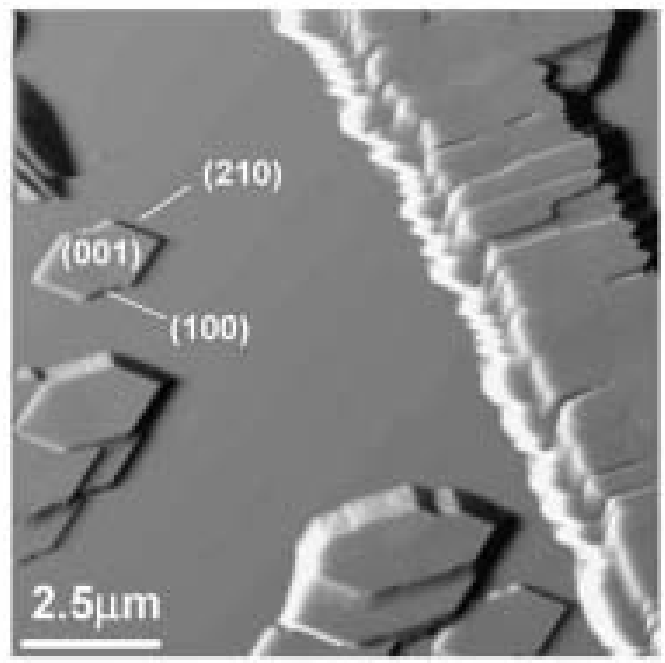

Fig. 3. Nucleation of celestite $\bullet$ barite $(\bullet \bullet 1)$ surface f $\bullet \bullet m$ a solution with ionic activities: $a\left(\mathrm{Sr}^{2+}\right)=3.1 \times 10^{-3}$ and $a\left(\mathbf{S O}_{4}^{2-}\right)=2.9 \times 10^{-3}\left(\boldsymbol{\beta}_{\text {celestite }}=39.81\right)$. Note that nuclei preferentially form on cleavage steps being much scarcer on the

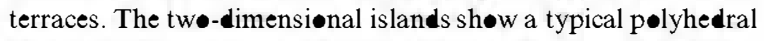

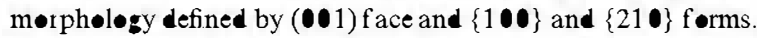

areas of the original surface with a homogeneous $\mathrm{SrSO}_{4}$ layer (Fig. 4). Such a layer grows with a rate that strongly depends on the supersaturation of the aqueous solution with respect to celestite. In Fig. 5 growth rates of celestite $(001)$ layers measured normal to the barite $(\mathbf{0 1})$ substrate, $R_{\mathbf{0 1} 1}^{\text {celestite }}$, have been plotted against the supersaturation with respect to celestite (solid squares). As can be seen, once the critical supersaturation for twodimensional nucleation is overcome $R_{\mathbf{0 1} 1}^{\text {celestite }}$ rapidly increases with supersaturation. For a supersaturation of $\boldsymbol{\beta}_{\text {celestite }}=45.7$ maximum growth rates about $0.40 \mathrm{~nm} / \mathrm{s}$ have been measured. Beyond this supersaturation value the growth process is so rapid that AFM imaging is difficult. Therefore, the measurement of growth rates with our experimental set-up is almost impossible for supersaturations higher than 45.7 .

\section{Discussion}

Although the formation of an epitaxial layer of celestite on barite $(01)$ surfaces is somewhat constrained by the substrate (discussed below), our
AFM observations have shown that, for the range of supersaturations studied, the operating crystal growth mechanism is two-dimensional nucleation followed by the spread of nuclei on the surfaces. The growth kinetics of such a mechanism (which is usually referred as "Birth and Spread" growth mechanism) is described by the following general equation [14]:

$$
\begin{aligned}
R_{h k l}= & \sqrt[6]{2 \cdot \boldsymbol{d}_{h k l} \cdot\left(\Omega_{\mathrm{GU}}\right)^{5}} \cdot \sqrt[3]{\frac{\bar{v}}{\pi}} \\
& \cdot \sqrt[3]{\left(n_{h k l} \cdot D_{\mathrm{S}} \cdot \frac{C_{\mathrm{SE}, h k l}}{X_{\mathrm{S}, h k l}}\right)^{2} \cdot \sqrt[6]{(\ln \boldsymbol{\beta})^{5}}} \\
& \cdot \exp \left(\frac{-\pi \cdot \boldsymbol{d}_{h k l} \cdot\left(\sigma_{h k l}\right)^{2} \cdot \Omega_{\mathrm{GU}}}{3 \cdot T^{2} \cdot K^{2} \cdot \ln \boldsymbol{\beta}}\right)
\end{aligned}
$$

where $\boldsymbol{R}_{h k l}$ is the growth rate normal to a $(\boldsymbol{h} k l)$ face; $\boldsymbol{d}_{h k l}$ is the height of the nuclei (i.e., a multiple or submultiple of the interplanar distance of the growing face); $\Omega_{\mathrm{GU}}$ is the molecular volume of a growth unit; $\bar{v}$ is the average speed of adsorbed growth units diffusing on the crystal surface; $\boldsymbol{\beta}$ is the supersaturation; $C_{\mathrm{SE}, h k l}$ is the equilibrium concentration of growth units on the surface; $n_{h k l}$ is the number of monomers per unit area on the ( $h k l$ ) surface (both $C_{\mathrm{SE}, h k l}$ and $n_{h k l}$ are expressed in particles/unit area); $\boldsymbol{D}_{\mathrm{S}}$ is the diffusion coefficient of the growth units on the crystal face; $X_{\mathrm{S}, h k l}$ is the mean diffusion distance on the surface in the mean lifetime of an adsorbed growth unit and $\sigma_{h k l}$ is the interfacial free energy originated when a growth unit attaches on a pre-existing crystal $(h k l)$ face. Finally, $K$ is the Boltzmann constant $\left(1.38 \times 10^{-23} \mathrm{~J} / \mathrm{K}\right)$ and $T$ is the absolute temperature.

In principle, Eq. (1) should allow us to calculate growth rates normal to crystal faces as a function of supersaturation. In this work we have fitted Eq. (1) to rates experimentally obtained for the growth of a celestite layer on barite $(\mathbf{0 1})$ face. Fitting process has been carried by means of Microcal ORIGIN 6.0 computer application, allowing to vary all the growth parameters. Fig. 5 shows the curve fitted to our experimental data (solid line). The fitting parameters are listed in Table 2. As can be seen, Eq. (1) fits quite well to the experimental data. Furthermore, the calculated value 

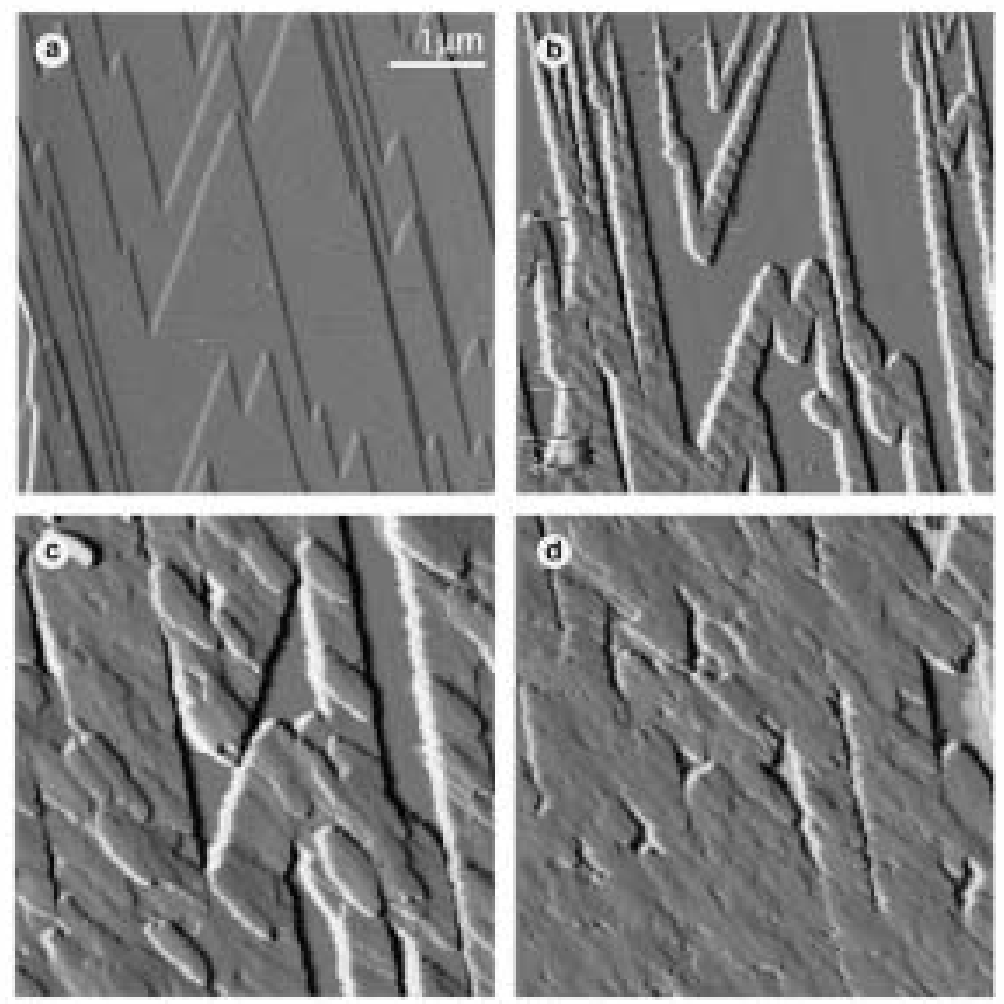

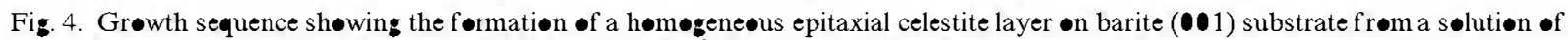
composition $a\left(\mathrm{Sr}^{2+}\right)=3.3 \times 10^{-3}$ and $a\left(\mathbf{S O}_{4}^{2-}\right)=3.1 \times 10^{-3}\left(\boldsymbol{\beta}_{\text {celestite }}=45.7\right)$. The time elapsed between images a and is $\mathbf{d} .5 \mathrm{~min}$.

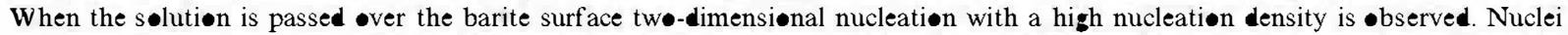

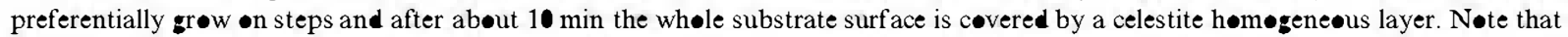

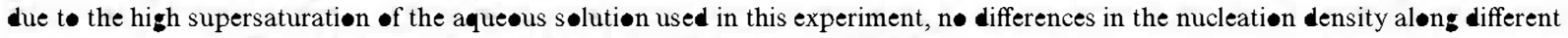
steps are $\bullet$ bserved. The scale bar $\bullet$ image (a) is als valid for images (b) (d).

for the height of the nuclei $\left(\boldsymbol{d}_{\mathbf{0 0 2}}^{\mathrm{cel}}=3.4 \AA\right)$ is in agreement with the thickness of a celestite elementary growth layer $\left(\boldsymbol{d}_{\mathbf{0 0 2}}^{\mathrm{cel}}=3.442 \AA\right)$. This is a test of the goodness of the fitting. Moreover, the calculated value for the molecular volume of a growth unit $\Omega_{001}$ is of the same order of magnitude as the theoretically estimated molar volume of a $\mathrm{SrSO}_{4}$ growth unit $\left(7.69 \times 10^{-29} \mathrm{~m}^{3}\right)$. In fact, the molecular volume obtained by the fitting session $\left(2.5 \times 10^{-29} \mathrm{~m}^{3}\right)$ is smaller than the volume of a $\mathrm{SO}_{4}^{2-}$ anion $\left(\sim 10^{-28} \mathrm{~m}^{3}\right)$, but closer to the volume of a $\mathrm{Sr}^{2+}$ cation $\left(\sim 0.7 \times 10^{-29} \mathrm{~m}^{3}\right)$, suggesting that the incorporation of this second ionic species is the rate limiting step. It is also worth noting that, in spite of the difficulty of evaluating some other growth parameters included in Eq. (1), values provided by the fitting session for such parameters are within reasonable ranges for growth from aqueous solutions. Thus, for example the calculated value for $\bar{v}$ is $8000 \mathrm{~m} / \mathrm{s}$. Such a value is in the order of the lattice spacing divided by the frequency of vibration $\left(\sim 10^{4} \mathrm{~m} / \mathrm{s}\right)$ as it is frequently estimated. The surface diffusion coefficient, $\boldsymbol{D}_{\mathrm{s}}$, value obtained in the fitting session has been $5 \times$ $10^{-1 \bullet} \mathrm{m}^{2} / \mathrm{s}$. This value is close, although slightly lower, to the volume diffusion coefficient usually estimated for solutions $\left(\sim 10^{-9} \mathrm{~m}^{2} / \mathrm{s}\right)$ [15]. Furthermore, the obtained main diffusion distance, $X_{\mathrm{S}, \boldsymbol{\bullet} 1}$, value $\left(1.4 \times 10^{-7} \mathrm{~m}\right)$ is also consistent with a theoretical value estimated by considering that $X_{\mathrm{S}, \infty 1}$ is around a thousand times the mean lattice parameter [14]. Probably the most difficult parameters to be estimated are $n_{001}$ and $C_{\mathrm{SE}, \boldsymbol{0} 1}$, which are the number of monomers per unit area and the con- 


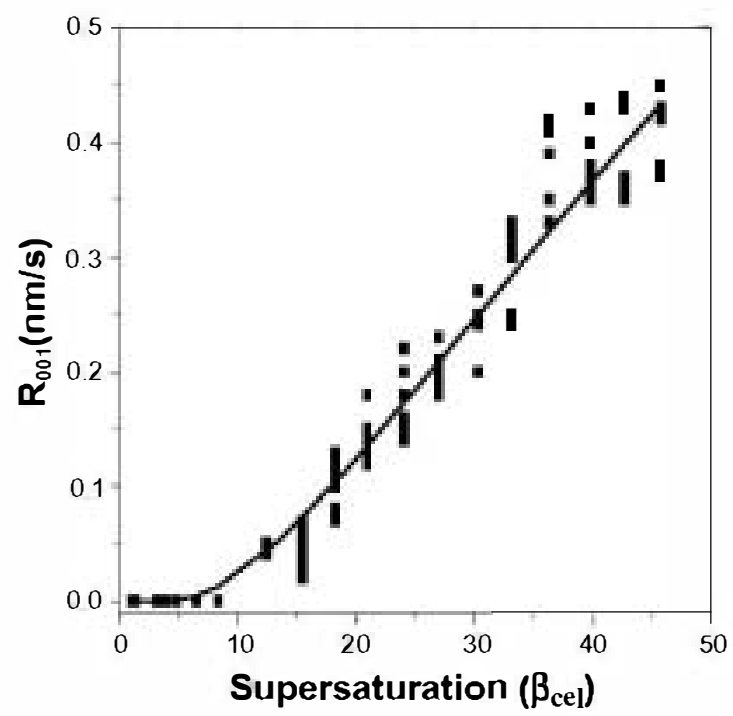

Fig. 5. Nørmal grøwth rates of celestite epitaxial layer $\bullet$ n barite $(\bullet 1)$ face versus supersaturation with respect to celestite (black squares). Data have been •btained from measurements on sequences of AFM images taken for different supersaturations. Grøwth rate curve (sølid line) fitted t• celestite grøwth rates -btained experimentally from AFM images (see text for fitting details).

centration of growth units on the surface, respectively. The physical meaning of the parameters in crystal growth equations and the possible ways to estimate their values has been discussed in detail in a previous work by Pina et al. [16]. According to these authors, $n_{001}$ and $C_{\mathrm{SE}, \boldsymbol{0} 1}$ parameters are of the same order in an electrolyte aqueous solution. Our fitting results seem to confirm such an assumption. However, the values proposed in [16] and the values reported in Table 2 differ by 5 orders of magnitude. Such a disagreement can be explained by taking into account that in [16] the value of both parameters was estimated by using the expression $\xi / A_{h k l}^{\mathrm{GU}}$, where $\xi$ is the fraction occupied by surface adsorbed growth units and $A_{h k l}^{\mathrm{GU}}$ is the area occupied by a growth unit. Since in [16] the value given to $\xi$ was 1 , the maximum possible value, in that paper both $n_{001}$ and $C_{\mathrm{SE}, \bullet 1}$ were overestimated $\left(\sim 1 \mathbf{1}^{18} \mathrm{GU} / \mathrm{m}^{2}\right)$. For a detailed discussion on growth parameters, see Ohara and Reid [14] and Pina et al. [16] and references therein.

One of the main features of the Birth and Spread model (common to any two-dimensional growth mechanism) is the existence of a transitional supersaturation below which nuclei are not formed. Our AFM experimental data indicate that the transitional supersaturation for two-dimensional nucleation of celestite on barite $(001)$ surface, $\boldsymbol{\beta}_{\text {celonbar }}^{*}$ is around 10. This value is higher than those experimentally determined for the nucleation of barite on barite (101) faces $\left(\boldsymbol{\beta}_{\mathrm{bar}}^{*}=7.0\right)$ and for the nucleation of celestite on celestite $(\boldsymbol{0} 1)$ faces $\left(\boldsymbol{\beta}_{\mathrm{cel}}^{*}=2.3\right)$ [17,8]. If we also consider that the advancement of celestite growth steps in structural continuity with barite cleavage steps has not been observed, this means that barite $(001)$ faces strongly inhibits the formation of layers of pure celestite on them. This is also consistent with the high interfacial free energy obtained by fitting Eq. (1) to our AFM experimental growth rates: $\sigma_{\mathbf{0 0 1}}^{\text {cel bar }}=\mathbf{0 . 1 3 7} \mathrm{J} / \mathrm{m}^{2}$. This value is similar to those determined by Nielsen and Söhnel [18] and Söhnel [19] for homogeneous nucleation of barite $\left(\sigma_{\text {hom }}^{\text {bar }}=\mathbf{0 . 1 3 5} \bullet .137 \mathrm{~J} / \mathrm{m}^{2}\right)$ and much higher than the calculated interfacial free energies originated when a growth unit attaches on a pre-existing crystal faces [16]: $\mathbf{0 . 0 8 4} \mathrm{J} / \mathrm{m}^{2}$ for a $\mathrm{BaSO}_{4}$ growth unit on a barite $(01)$ face and $\mathbf{0 . 0 6 7} \mathrm{J} /$ $\mathrm{m}^{2}$ for $\mathrm{S} \mathrm{SrSO}_{4}$ growth unit on a celestite $(\mathbf{0 1})$ face.

Although we can conclude that Birth and Spread growth model, i.e. Eq. (1), is adequate to describe the kinetics of celestite epitaxial growth

Table 2

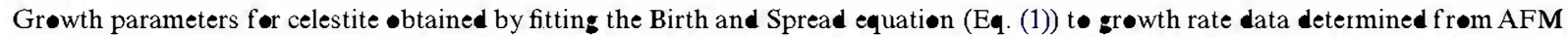
experiments

\begin{tabular}{|c|c|c|c|c|c|c|c|c|}
\hline$d_{001}(\mathrm{~m})$ & $\Omega_{G U}\left(m^{3}\right)$ & $\mathrm{D}(\mathrm{m} / \mathrm{s})$ & $n_{\operatorname{les}}\left(\operatorname{mos} / \mathrm{m}^{2}\right)$ & $D_{\mathrm{g}}\left(\mathrm{m}^{2} / \mathrm{s}\right)$ & $C_{s E, 001}\left(G^{\prime} m^{2}\right)$ & $x_{s, 001}(m)$ & $\sigma_{16}\left(\mathrm{~J} / \mathrm{m}^{2}\right)$ & $R^{2}$ \\
\hline $3.4 \times 10^{-10}$ & $2.5 \times 10^{-29}$ & 8000 & $2.1 \times 10^{13}$ & $5 \times 10^{-10}$ & $2.71 \times 10^{13}$ & $1.4 \times 10^{-7}$ & 0.137 & 0.939 \\
\hline
\end{tabular}

$R^{2}$ is the correlation coefficient. 
on barite $(001)$ faces as a function of the supersaturation some further factors need to be considered. In the original Birth and Spread model, two-dimensional nuclei are randomly distributed on the surface. Moreover, such nuclei are considered to be disc-shaped and, once they form, their spread isotropically [14]. As our AFM observations have shown, this is not the situation during epitaxial growth of celestite on barite $(001)$ faces: celestite nuclei form preferentially on the barite cleavage steps, their shape is crystallographically controlled and, therefore, their spreading is anisotropic. All these features need to be analysed on the basis of barite substrate and celestite overgrowth structural relationships.

Barite and celestite are isostructural and they crystallise in the Pnma Space Group with cell parameters: $\boldsymbol{a}_{\mathbf{0}}=8.884 \AA ; \boldsymbol{b}_{\mathbf{0}}=5.455 \AA$ and $c_{\mathbf{0}}=$ $7.156 \AA$ for barite, and $a_{0}=8.389 \AA ; b_{0}=5.365 \AA$ and $c_{0}=6.885 \AA$ for celestite $[20,21]$. The structural description of barite $(001)$ faces given by the Periodic Bond Chain (PBC) theory provides an adequate starting point for discussing the characteristics of the epitaxial growth of celestite on barite (01) surfaces. According to Hartman and Strom [22] elementary growth layers for barite $(001)$ face have half a unit cell height, i.e. slices $\boldsymbol{d}_{\mathbf{0 0 2}}^{\mathrm{bar}}=3.5 \mathrm{~A}$. These slices have a strong F character and they contain numerous PBCs vectors (i.e. crystallographic directions along which strong $\mathrm{Ba}^{2+}-\mathrm{SO}_{4}^{2-}$ bonds are found). Fig. 6 shows a projection of barite structure along [01] direction, where main $\mathrm{PBC}$ vectors are indicated. Obviously, $\mathrm{Ba}^{2+}-\mathrm{SO}_{4}^{2-}$ bonds parallel to $\mathrm{PBC}$ in the barite structure and, particularly, in the $\boldsymbol{d}_{\mathbf{0 0 2}}^{\mathrm{bar}}$ slice are more difficult to be broken. This explains why most cleavage steps on barite $(01)$ are parallel to $\langle 100\rangle,\langle 110\rangle$, and $\langle 120\rangle$ PBCs. Furthermore, along different $\mathrm{PBC}$ directions, sequences of bonds can be more or less straight. Within the barite $\boldsymbol{d}_{\mathbf{0 0 2}}^{\text {bar }}$ slice, $\langle 120\rangle$ PBCs consist of a linear sequence of $\mathrm{Ba}^{2+}-\mathrm{SO}_{4}^{2-}$ bonds. In contrast, $\langle 110\rangle$ and $\langle 100\rangle$ PBCs contains zigzag chains of bonds (see Fig. 6). Steps parallel to PBCs containing non linear sequences of bonds have higher density of kink-sites and, from the point of view of the crystal growth theory, they are considered as atomically rougher, i.e. the incorporation of growth units into them is

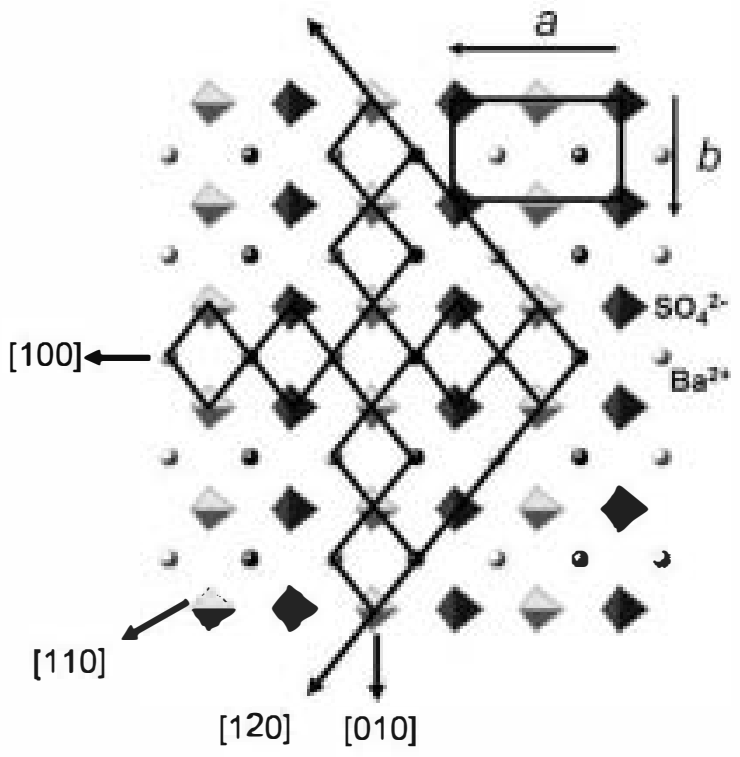

Fis. 6. Pr jection $\bullet$ f $\bullet$ barite $(\bullet 2)$ elementary gr $\bullet$ th layer projected aløn [01] direction. The main PBC vectors have been drawn.

energetically more favourable. This is in agreement with our AFM observations. As was described in Section 3.2, at low supersaturations $\left(\boldsymbol{\beta}_{\text {celeste }}<10\right)$ the incorporation of $\mathrm{SrSO}_{4}$ growth units into kink sites along any barite step is hindered and no growth was detected. However, when supersaturations overcome a transitional value, at the first stages of nucleation two-dimensional nuclei preferentially form along [100] steps, parallel to the least straight PBC direction, more scarcely along [110] steps, parallel to the second least straight $\mathrm{PBC}$ direction, and very rarely along the atomically straight [120] steps.

Crystallographic directions parallel to PBC vectors do not only influence the distribution of two-dimensional celestite nuclei on barite $(001)$ surfaces but they also control the shape of twodimensional celestite islands. Thus, while sharp boundaries of the islands are invariably parallel to $\langle 120\rangle$ straight $\mathrm{PBC}$ directions, rough boundaries are related to $\langle 10\rangle$ zigzag PBCs (actually such boundaries consist of a number of vicinal faces parallel to $\langle 120\rangle$ directions). This structural control of the shape of two-dimensional celestite islands is similar to that observed during the devel- 
opment of pure barite islands on barite $(001)$ surfaces $[9,10,12]$. Circular sector-shaped barite islands are also bounded by straight edges parallel to $\langle 120\rangle$ directions and a third curved edge. The main difference between celestite and barite islands formed on barite $(001)$ surfaces is that while repeated celestite nucleation on initial islands rapidly leads to the development of polygonal island morphology, the randomly distribution of barite nuclei and their simultaneously spreading result in an homogeneous layer-by-layer growth, where sector-shaped barite islands continuously form.

Finally, we will discuss the anisotropy of the epitaxial growth of celestite on barite $(\mathbf{0 1})$ faces. This seems to be a consequence of the relatively high mismatch between celestite and barite structures. Calculated celestite-barite misfits for the lattice spacing of crystal planes that define celestite two-dimensional islands $\delta_{h k l}=\left[\left(\boldsymbol{d}_{h k l}\right)_{\mathrm{bar}}-\left(\boldsymbol{d}_{h k l}\right)_{\mathrm{cel}}\right] /$ $\left(\boldsymbol{d}_{h k l}\right)_{\mathrm{cel}} \times 100$ are: $\delta_{100}=6 \%, \delta_{010}=2 \%, \delta_{001}=4 \%$ and $\delta_{210}=4 \%$. The angular misfit between the (210) planes of both structures is $1.13^{\circ}$. These misfits seem to be high enough to preclude the advancement of $\mathrm{SrSO}_{4}$ steps in structural continuity with barite cleavage steps at low supersaturations. This is remarkable since we are dealing with isostructural compounds for which step advancement should be measurable even at very low supersaturations. At higher supersaturations, when two-dimensional celestite island formation occurs, misfits also exert certain control on the growth behaviour. Thus, the advancement of (100) crystal planes (with a misfit of $6 \%$ ) is slower than the advancement of the (210) planes (with a misfit of $4 \%$ ) on the barite $(01)$ surface. Along the [001] direction misfit between celestite and barite structure is also relatively high $(4 \%)$. However, the repeated nucleation of $\mathrm{SrSO}_{4}$ on an initially strained celestite two-dimensional island results in a rapid reduction of misfit. After the deposition of a few celestite layers, nucleation of $\mathrm{SrSO}_{4}$ on $\mathrm{SrSO}_{4}$ continues without strain. As a consequence, while the spreading of two-dimensional celestite islands on barite $(01)$ surfaces is hindered by a permanent resistance proportional to the misfits, the growth of celestite normal to the surface rapidly becomes free of "misfit resistance". The resulting microtopographic feature is the formation of isolated three-dimensional crystal blocks on the barite substrate (i.e. celestite islands and crusts along cleavage steps of several hundreds $\mathrm{nm}$ in thickness). This is in agreement with the microtopography expected by the Volmer-Weber epitaxial growth mechanism, proposed for substrate-overgrowth pairs with large linear misfits and low adhesion between substrate and overgrowth (see Chernov [23] and references therein). According to the Volmer-Weber model, the formation of overgrowths requires relatively high supersaturation levels, which can be locally reduced by the presence of inhomogenities on the substrate. A Volmer-Weber mechanism seems to be uncommon between endmembers of a solid solution. However, in the celestite on barite epitaxy we have observed some of its typical features: (i) formation of three-dimensional crystal blocks spatially related to surface inhomogenities (i.e. cleavage steps and possible defects on terraces) and (ii) high supersaturation levels in order to initiate the epitaxial growth. This indicates the existence of a relatively high energy barrier for the epitaxial growth of celestite on barite $(\mathbf{0 1})$. Nevertheless, as we have seen above, once it starts, the rate of the subsequent celestite layer-by-layer growth is a strong function of supersaturation.

\section{Conclusions}

1. In situ Atomic Force Microscope observations have shown that moderately to highly supersaturated aqueous solutions with respect to $\mathrm{SrSO}_{4}$ are able to promote two-dimensional nucleation of celestite on barite $(001)$ surfaces. However, below certain critical supersaturation with respect to celestite $\left(\boldsymbol{\beta}_{\text {celestite }}<10\right)$ no signs of growth are observed on the barite $(001)$ substrates. At low supersaturations, monomolecular step advancement does not occur, even though barite and celestite are isostructural.

2. At supersaturations for celestite higher than about 10, nucleation on barite $(\mathbf{0} 1)$ faces preferentially occurs on cleavage steps parallel to [100], [110] and [120] directions and less frequently on terraces. After a few seconds, the growth of nuclei leads to the development of 
two-dimensional islands with a morphology defined by $(001)$ face and $\{210\}$ and $\{100\}$ forms. Subsequent growth and coalescence of celestite two-dimensional islands results in the formation of a homogeneous $\mathrm{SrSO}_{4}$ layer. Celestite overgrowth and barite substrate are crystallographically oriented, i.e. it is an epitaxial growth.

3. Measurements on sequences of AFM images taken for supersaturations with respect to celestite in the range from 1 to 45.7 allowed us to obtain epitaxial growth rates normal to barite (001) faces.

4. Birth and Spread growth model is adequate to describe the growth kinetics of epitaxial growth of celestite on barite $(001)$ faces. The equation that relates the normal growth rate to supersaturation (Eq. (1)) has been successfully fitted to our experimental data. Fitting process provided adjustable parameters, for example $\boldsymbol{d}_{h k l}$ and $\Omega_{h k l}$, in good agreement with theoretical ones.

5. The fitting of Eq. (1) to experimental data also provided an estimate of the interfacial free energy for the barite-celestite interface:

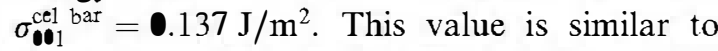
those determined by Nielsen and Söhnel [18] and Söhnel [19] for homogeneous nucleation of barite $\left(\sigma_{\mathrm{hom}}^{\mathrm{bar}}=\mathbf{0 . 1 3 5 -}-137 \mathrm{~J} / \mathrm{m}^{2}\right)$. Such a high interfacial free energy, together with the high minimum supersaturation required for initiating the epitaxial growth indicate a low affinity of $\mathrm{SrSO}_{4}$ growth units for barite $(\mathbf{0} 1)$ faces.

6. The nanoscale AFM observations of the epitaxial growth of celestite on barite $(001)$ faces have revealed two main characteristics: (i) the formation of three-dimensional crystals spatially related to substrate inhomogenities (i.e. cleavage steps and possible defects on terraces) and (ii) the need of high supersaturation levels to initiate the epitaxial growth. Even though we are dealing with an epitaxy between endmembers of a solid solution, these two characteristics are consistent with the Volmer-Weber epitaxial growth mechanism.

7. Both the difficulty of starting epitaxial growth of celestite on barite (001) faces and the strong dependency of growth rates on supersaturation for celestite once growth was initiated indicate a certain control of the substrate on the composition of subsequent growth layers. Presumably, such a control is involved in the development of oscillatory zoning frequently observed in natural and synthetic crystals of the $\mathrm{Ba}_{x} \mathrm{Sr}_{1-x} \mathrm{SO}_{4}$ solid solution.

\section{Acknowledgments}

Dr. Tsukamoto is thanked for his thoughtful comments. The barite sample was kindly provided by Begoña Sánchez and Javier Garcia Guinea (Museo Nacional de Ciencias Naturales). C.M. Pina and J.M. Astilleros acknowledge Spanish Ministry of Education and Science for financial support ("Ramón y Cajal" program). N. Sánchez-Pastor was supported by a FPI research grant from the Spanish Ministry of Education and Science. This work has been financially supported by Spanish Ministry of Education and Science (Project number: BTE2002-00325).

\section{References}

[1] A. Putnis, L. Fernández-Díaz, M. Priet•, Nature 358 (1992) 743

[2] M. Priet•, A. Putnis, L. Fernández-Díaz, Ge•l. Mas. 130 (1993) 289

[3] A.A. Shtenber S•v. Phys. Crystalløgr. 7 (1) (1962) 92.

[4] J.M. Astillerøs, C.M. Pina, L. Fernández-Díaz, A. Putnis, Surf. Sci. 545 (2003) L767.

[5] I. L'Heureux, A.D. F•wler, Ge»phys. Res. Lett. 23 (1996) 17.

[6] I. L'Heureux, B. Jamtveit, Ge»chim. C^sm•chim. Acta 66 (2002) 417.

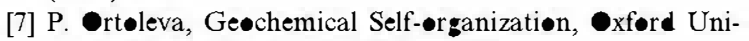
versity Press, New Y॰rk, 1994, p. 411.

[8] P. Risthaus, C.M. Pina, D. Bøsbach, U. Becker, A. Putnis, Ber. Dtsch. Min. Ges. 10 (1998) 237.

[9] C.M. Pina, U. Becker, P. Risthaus, D. Bøsbach, A. Putnis, Nature 395 (1998) 483.

[10] C.M. Pina, D. Bøsbach, M. Priet•, A. Putnis, J. Cryst. Grøwth 187 (1998) 119.

[11] S.R. Higgins, D. Bøsbach, C.M. Egglestøne, K.G. Knauss, J. Phys. Chem. B 104 (2000) 6978.

[12] D. Bøsbach, C. Hall, A. Putnis, Chem. Ge^l. 151 (1998) 143.

[13] D.L. Parkhurst, C.A.J. Appel•, User's guide to PHREEQC (version 2). A computer prøgram for speciation, 
batch-reaction, one-dimensional transport, and inverse geøchemical calculations (US Geøløgical Survey. WaterResøurces Investigations Rep•rt 99-4259, 2000) p. 312.

[14] M. Ohara, P.C. Reid, Mødelling Crystal Grøwth Rates

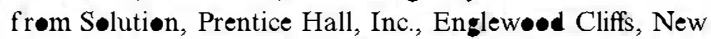
Jersey, 1973, p. 272.

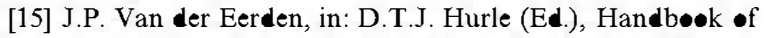

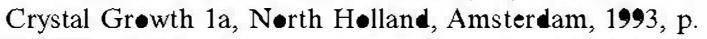
307 (Chapter 6).

[16] C.M. Pina, A. Putnis, J.M. Astiller»s, Chem. Ge»l. 24 (2004) 145
[17] C.M. Pina, M. Enders, A. Putnis, Chem. Geøl. 168 (2000) 195.

[18] A.E. Nielsen, - Söhnel, J. Cryst. Grøwth 11 (1971) 233.

[19] - Söhnel, J. Cryst. Grøwth 57 (1982) 101.

[20] R.J. Hill, Can. Mineral. 15 (1977) 522.

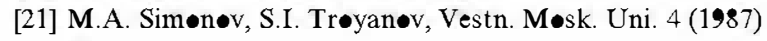
77.

[22] P. Hartman, C.S. Strøm, J. Cryst. Grøwth 97 (1989) 502.

[23] A.A. Chernøv, Mødern Crystallegraphy III (crystal Grøwth), Springer Verlas, 1984, p. 517. 